\title{
Optimizing Use in the Field of Program Evaluation by Integrating Learning from the Knowledge Field
}

Catherine Donnelly

Queen's University

Michelle Searle

Independent Consultant

\begin{abstract}
It has been almost 20 years since Shulha and Cousins (1997) published their seminal paper exploring evaluation use. The paper examined a decade, 1986 to 1996, of theory, practice, and research on evaluation use. Since that time there have been significant developments related to the phenomenon of evaluation use. Outside of evaluation a new and burgeoning field has focused on the use of research in practice and policy; in health care the term knowledge translation has been used and in social sciences knowledge mobilization. Despite the rapidly growing body of research from the knowledge field, the different terminology used in evaluation, health care, and the social sciences has created siloed bodies of knowledge, even when working on similar change processes. This may be one of the factors why the large body of literature on evaluation use has received little attention in health care and vice versa. The aim of this article is threefold: first, to examine the developments in evaluation use since Shulha and Cousins's (1997) paper; second, to explore how the knowledge fields, focusing on knowledge translation and mobilization, can help to further refine and develop our understanding of use; and third, to imagine what future research that interweaves the knowledge field with the field of program evaluation might look like and how it has the potential to serve the contexts where this research would be conducted.
\end{abstract}

Keywords: evaluation use, knowledge mobilization, knowledge translation

Résumé : Il y a presque 20 ans que Shulha et Cousins (1997) ont publié leur article phare sur l'utilisation de lévaluation. Leurs travaux ont examiné une décennie, de 1986 à 1996, de théorie, pratique et recherches sur l'utilisation de lévaluation. Depuis lors, il y a eu d'importants développements liés au phénomène de l'utilisation de l'évaluation. Au-delà de l'évaluation, un nouveau domaine s'est développé sur l'utilisation de la recherche dans la pratique et les politiques; en santé, le terme transfert des connaissances a été utilisé et en sciences sociales, on parle de mobilisation du savoir. Malgré le corpus rapidement grandissant de recherches dans le domaine des connaissances, les différentes terminologies

Corresponding Author: Catherine Donnelly, School of Rehabilitation Therapy, Louise D. Acton Building, 31 George Street, Queen's University, Kingston, ON K7L 3N6 Canada; catherine.donnelly@queensu.ca 
utilisées dans les domaines de l'évaluation, des sciences de la santé et des sciences sociales ont créé des silos, alors ce sont les mêmes processus de changement qui sont analysés. Ceci pourrait en partie expliquer pourquoi les écrits sur l'utilisation de l'évaluation ont reçu peu d'écho dans le domaine de la santé, et vice-versa. Cet article a trois objectifs : premièrement, d'examiner les développements en utilisation de l'évaluation depuis l'article de Shulha et Cousins (en 1997); deuxièmement, d'explorer la façon dont les domaines de connaissance, axés sur le transfert des connaissances et la mobilisation du savoir, peuvent nous aider à mieux comprendre l'utilisation; et troisièmement, d'imaginer les pistes de recherche à cheval sur le domaine de l'utilisation des connaissances et celui de lévaluation de programme, et d'analyser leur intérêt pour les contextes dans lesquels ces travaux seraient menés.

Mots clés : utilisation de lévaluation, mobilisation du savoir, transfert de connaissances

\section{INTRODUCTION}

Use has been an object of scholarly writing and empirical research in the field of evaluation for almost four decades (Alkin \& Taut, 2003; Greene, 1988; King \& Pechman, 1984; Patton, 2007; Shulha \& Cousins, 1997; Suchman, 1967; Weiss, 1972). Evaluators are concerned with the way information from an evaluation process and/or the products are used in practice and decision making. Christie (2007) stated that "evaluation utilization is arguably the most researched area of evaluation and it also received substantial attention in the theoretical literature" (p. 8). Similarly, Contandriopoulos and Brousselle (2012) commented that "use is at the core of every evaluation endeavour" (p. 61). We considered multiple definitions in exploring this concept; three definitions that resonated for us are positioned here.

- Alkin and Taut (2003) reported that use is "the ways in which an evaluation and information from the evaluation impacts the program that is being evaluated" (p. 1).

- Patton (2008) identified use as "how real people in the real world apply evaluation findings and experiences" (p. 37).

- Johnson et al. (2009) described use as "the application of evaluation process, products, or findings to produce an effect" (p. 378).

Much could be said about the differences or the scholars who have put forth these ideas; however, common to all these definitions is the notion that use includes results or findings from an evaluation as well as the process of the evaluation.

Outside of evaluation is a burgeoning field focused on the use of research in practice and policy. In health care the term knowledge translation (KT) has been used and in social sciences knowledge mobilization $(\mathrm{KMb})$; recently the term $\mathrm{K}^{*}$ has been used capture this field of research. This field is fundamentally interested in how knowledge, in the form of ideas, innovation, or skills, moves in some direction among a group of stakeholders as they are situated within their specified 
contexts. In this article, we explore the recent developments in the area of evaluation use to consider how work drawn from the field of $\mathrm{K}^{\star}$ contributes to new understandings and actions in evaluation contexts. Integrating learning from the study of use in the field of evaluation as well as solutions from the knowledge field may better equip evaluators to improve access to evidence and encourage the use of evidence in decision making.

\section{BACKGROUND}

The seminal paper published by Shulha and Cousins (1997) is an apt starting place for exploring evaluation use in this special issue that is dedicated to Dr. L. M. Shulha. The paper examined a decade, 1986 to 1996, of theory, practice, and research on evaluation use. Since that time there have been significant developments related to the phenomenon of evaluation use. In 1996 process use had recently been introduced and now, 20 years later, is a well-accepted concept. Consideration of context, which was just emerging, is now seen as fundamental to evaluation use. The Program Evaluation Standards (Yarbrough, Shulha, Hopson, \& Caruthers, 2011) are now in their third edition, and Lyn's commitment to the area of use can be seen in the Standards where utility is placed as the first standard due to its significance in determining the worth of evaluation process, findings, and products. Notably, Lyn has made significant contributions to the initial evaluation literature on use and has made progressive contributions to the study of use since then.

During Lyn's time as a faculty member at Queen's University she mentored both authors of this article in thinking about how to enhance the use of evaluation in their respective areas of inquiry: health and education. Understanding evaluation scholarship that is accessible to a range of stakeholders is a passion and commitment that Lyn Shulha championed. Returning to graduate school after time invested as practitioners strengthened our desires to engage in program evaluation as a form of applied research that provided reciprocal and transdisciplinary benefits in our respective professional fields. In other words, both authors felt strongly that our evaluation scholarship should inform and be informed by the communities in which we practice as well as the research communities beyond the specific disciplines of evaluation, health, or education. As associate members of the Queen's University Assessment and Evaluation group, the authors were mentored on diverse projects that focused on using collaborative and participatory models to enhance stakeholder engagement and draw out multiple forms of evidence. As we started to think about the contributions of our work with Lyn and beyond, we began to wonder about the interconnections between evaluation use, the knowledge field, and our respective disciplines.

The aim of this article is threefold: first, to examine the developments in evaluation use since Shulha and Cousins's (1997) paper; second, to explore how the knowledge fields, focusing on knowledge translation and mobilization, can help to further refine and develop our understanding of use; and third, to imagine what future research that interweaves the knowledge field with the field 
of program evaluation might look like and how it has the potential to serve the contexts where this research would be conducted.

\section{SITUATING EVALUATION USE: AN OVERVIEW OF KEY DEVELOPMENTS}

We draw on several literature reviews on evaluation use that have been completed over the past 20 years (e.g., Johnson et al., 2009) to identify two key developments in the area of evaluation use. The first key development focuses on individual and organizational learning and encompasses process use, the influence of stakeholder involvement, and the oft-resulting evaluation capacity building. A second major development stems from the thinking about evaluation use and evaluation influence. Within each key area of development we identify the conceptual significance, establish its current positioning, and show how this development has readied the field of program evaluation to draw from the field of $\mathrm{K}^{\star}$.

\section{Key Development One: Individual and Organizational Learning}

\section{Process Use}

In 1997 there was agreement that use was a multidimensional phenomenon and one that was an iterative process. Weiss (1998) emphasized, "originally all we thought about was findings" and expected that people would use them (p. 21). Process use brought an emergent gaze that required attentiveness to the qualities that unfold during an evaluation. Cousins and Shulha (2006) stated:

possibly the most significant development of the past decade in both research and evaluation communities has been a more general acceptance that how we work with clients and practitioners can be as meaningful and consequential as what we learn from our methods. (p. 277; emphasis in original)

Evaluation scholars have established that we can learn as much from the process of evaluation as we can learn from the findings.

The field of evaluation conceptualizes process use as the types of learning that take place, intentionally and unintentionally, by stakeholders who are involved in a program evaluation. Amo and Cousins (2007) have referred to process use as a "by-product of evaluation" (p. 6). During involvement, participants might increase their knowledge, skills, or understanding. Credited with being the first evaluator to define process use, Patton (2008) called it:

[i]ndividual changes in thinking, attitudes, and behaviour, and program or organizational changes in procedures and culture that occur among those involved in evaluation as a result of the learning that occurs during the evaluation process. (p. 15)

Notable in this definition is the recognition that change occurs at both the individual and organizational level. Process use is now recognized as a central 
feature in collaborative, participatory, and utilization-focused approaches to evaluation (e.g., Alkin \& Taut, 2003; Cousins, Goh, Clark, \& Lee, 2004; Preskill, Zuckerman, \& Matthews, 2003). The connection between process use and participant-oriented approaches is not surprising, since these approaches each focus on the learning that occurs during an evaluation (Patton, 2007).

\section{Stakeholder Involvement}

Stakeholder involvement is another area that has received increasing attention in the past two decades and is closely related to process use (Brandon \& Fukunaga, 2013; Preskill \& Boyle, 2008). While the evaluation use literature has long recognized that including stakeholders increased the likelihood of evaluation utilization (e.g., Cousins \& Earl, 1992; House \& Howe, 1999; Patton, 1998; Rich, 1997), a literature review on evaluation use highlights that research examining the impact of stakeholder involvement on evaluation use is more recent. Johnson and colleagues (2009) reviewed the empirical literature on evaluation use from 1986 to 2005 and applied Cousins and Leithwood's (1986) original framework for categorizing studies on use. Based on the nature of studies that were identified, Johnson et al. (2009) added a category, stakeholder involvement, to capture the increased focus of this dimension in supporting evaluation use. Of their included studies, 23 of the 41 addressed stakeholder involvement.

Evaluation theorists and practitioners now resoundingly agree about the benefits in involving stakeholders. A survey of American Evaluation Association (AEA) members found that $98 \%$ of respondents felt that one of the primary roles of evaluators is to engage stakeholders (Fleischer \& Christie, 2009). Stakeholder involvement, which encourages process use, is now seen as critical in both supporting the learning function of evaluation (Preskill, Zuckerman, \& Matthews, 2003) and fostering "results that stakeholders understand and use" (Cousins, Whitmore, \& Shulha, 2013, p. 14). Yet, more information about how stakeholder involvement occurs in practice is needed. Brandon and Fukunaga (2013) conducted a systematic review of the literature on stakeholder involvement and found that research in this area is limited, relying on simple designs and data collection and occurring in only a handful of disciplines.

Evaluators and evaluation scholars recognized the need to develop new/ different skills to support stakeholder involvement. Cousins and Earl (1992) underscore one of the key tensions when involving stakeholders: evaluators need to balance being responsive with also possessing technical sophistication and managing for biases while establishing credibility. This echoes Shulha and Cousins's (1997) caution about the ability of evaluators to maintain a bias-free stance. Ongoing empirical research continues to look at the intended and unintended consequences of stakeholder involvement to provide evidence and ideas that enhance the advantages while minimizing limitations. As Taut (2008) states, "we need even more rich, detailed descriptions of successful and unsuccessful evaluations involving stakeholders" (p. 229).

Conversations at AEA suggest that we need clarifying frameworks for thinking about stakeholder involvement (Cousins, Whitmore, \& Shulha, 2013; 
Fetterman, Rodríguez-Campos, Wandersman, \& O’Sullivan, 2014). More recently, Shulha et al. (2016) proposed eight principles to guide collaborative approaches to evaluation: (a) clarify motivation for collaboration, (b) foster meaningful relationships, (c) develop a shared understanding of the program, (d) promote appropriate participatory processes, (e) monitor and respond to resource availability, (f) monitor evaluation progress and quality, (g) promote evaluative thinking, (h) follow through to realize use. Going forward, empirical testing of these principles can reveal the relationship between forms of stakeholder involvement, instances of process use, and use of both intentional and unintentional processes for building evaluation capacity.

\section{Evaluation Capacity Building}

Evaluation capacity building (ECB) has become an important topic in the evaluation community over the past decade (Preskill \& Boyle, 2008; TaylorPowell \& Boyd, 2008). We highlight ECB as a major development that brings together the concepts discussed so far: evaluation use, process use, participatory approaches, and collaborative frameworks for stakeholder involvement. Labin, Duffy, Meyers, Wandersman, and Lesesne (2012) define ECB as "an intentional process to increase individual motivation, knowledge, and skills, and to enhance a group or organization's ability to conduct or use an evaluation" (p. 2). Others have also proposed definitions of $\mathrm{ECB}$, and each includes the core features about the intentionality of practice and levels of change (Preskill \& Boyle, 2008; Stockdill, Baizerman, \& Compton, 2002). To understand the implications of ECB to evaluation use and the knowledge field, it is important to note that ECB is not only about capacity to do evaluation but also to use evaluation. Therefore organizations not only engage in ongoing inquiry but also continually use the emerging and contextual findings.

While process use also results in individuals and organizations learning about evaluation, ECB is unique in that it includes "clearly identified objectives" (Preskill \& Boyle, 2008, p. 450). It is this intentionality that ensures maximum learning both from and about the evaluation (Harnar \& Preskill, 2007). A growing body of empirical evidence has demonstrated support for the role of ECB in engaging in evaluation activities (Duffy \& Wandersman, 2007), building evaluation skills (Arnold, 2006; Taylor-Powell \& Boyd, 2008), increasing individual and organizational commitment to evaluation (Compton, Baizerman, Preskill, Rieker, \& Miner, 2001), creating positive attitudes toward evaluative inquiry (Atkinson, Wilson, \& Avula, 2005), and enhancing use of evaluation findings (Compton et al., 2001; Lawrenz, Thomas, \& Clarkson, 2008).

In a systematic review, Labin and colleagues (2012) examined the strategies used to support ECB and the outcomes at both individual and organizational levels. They found that $80 \%$ of ECB strategies were regularly based in some theory or principle, most notably theories and principles related to active learning (Labin et al., 2012). Several direct (workshops, training programs) and indirect strategies (participating in the evaluation) were used, and the importance of using strategies 
tailored to the context was highlighted. In terms of the outcomes of ECB, the authors found that $92 \%$ of the articles reported change at the level of individual change and $77 \%$ of the cases demonstrated organizational change. Unfortunately, the exact outcomes used to determine change were not reported in the study, and the authors acknowledge the very limited reporting of measures and quantitative data as a weakness of the study.

In 2007, Compton and Baizerman stated, "the ECB tent is still big, it is still open, and there is still room to conceptualize, implement, assess, analyze, and write" (p. 199). Similarly, Labin and colleagues (2012) believe there is room for continued sophistication, while Preskill and Boyle point to ECB as a "social epidemic of evaluation" (Preskill \& Boyle, 2008, p. 14) where diffusion is used for evaluation learning to flow within and across different dimensions, through networks that transfer and even enhance the evaluation thinking and practice.

\section{Key Development Two: Evaluation Use and Influence}

Theory of Influence. A second key development is related to the concept of influence. Some have suggested that use looks at direct impact whereas influence looks at the indirect forms of use. Kirkhart (2000), however, positions influence as an expanded form of use that offers more precise language to describe the impact of evaluations. Influence, she asserts, "can be examined from multiple vantage points" (p. 6). She offers an integrated model built on prior concepts and conversations that calls for a more comprehensive understanding about the effects of program evaluation.

Kirkhart (2000) is not the first or only evaluator to note the need to attend to language. Patton (2000) highlighted the importance of language in our understanding and perceptions of concepts and contexts. Twenty years ago evaluation was shifting away from the term "utilization" - a term that Weiss (1981) felt connoted "inappropriate imagery" - to the term "use." Kirkhart (2000) countered that "use" also does not account for the many ways both evaluation findings and processes may affect individuals and organizations. She proposed the term "influence" along with an Integrated Theory of Influence to enable a more multifaceted look at the effects of evaluation. In her theory, Kirkhart (2000) includes three dimensions: (a) source, (b) intention, and (c) timeframe. The dimensions of influence are seen as nonlinear, multifactorial, and interactive. Jonson, Guetterman, and Thompson (2014) suggest that Kirkhart's (2000) reconceptualization "extends the purposes of aims of assessment and evaluation beyond problem solving that leads to decision making to also include learning, that is, new or enhanced understandings that facilitate meaning making ... for improving ... practices and policies" (p. 21). They have linked, as we do, her theory of influence to social learning theory of constructivism and identified changes at individual and organizational levels.

At about this same time Henry and Mark (2003) also agreed that influence was a better term but focused on the need for evaluation to examine the 
change processes "through which evaluation findings and process may translate into steps toward social betterment" (p. 294). They offered a framework that articulates multiple levels, pathways, and mechanisms to explain the influence of evaluation (Henry \& Mark, 2003; Mark \& Henry, 2004). A key foundation of their work is that the ultimate goal of evaluation is social betterment. To achieve social betterment, changes resulting from an evaluation need to be linked back to the evaluation processes. Henry and Mark (2003) view evaluation as an intervention and offer a framework to understand the influence of evaluation at three levels: individual, interpersonal, and collective (organizational). Pathways link evaluation activities and influence. The use of pathways provides a mechanism to explore causal relationships and would enable the identification of change processes that may occur during evaluation, allow researchers to understand the more specific dimensions of evaluation influence and interactions at each level, and lastly support a variety of research, including quantitative studies on context and processes.

Herbert (2014) completed a review of the literature on evaluation influence, and articles that referenced either Kirkhart's (2000) or Mark and Henry's (2004) models of influence were included. The objective of the review was to examine the current state of evaluation influence research and understand how influence has been used as a concept to consider the impact of evaluations. The review identified 28 articles, and while the concept of influence has been adopted in the literature, the empirical evidence is considerably lacking. Much of the research was descriptive in the sense that influence was used to describe the evaluation and only 4 studies had specific hypotheses that they sought to test. Overall the studies were of poor methodological quality, and Herbert concluded that the research to date has done little to build a body of evidence on influence that can support evaluation practice.

The integration of ideas about stakeholder involvement, ECB, and influence brings us full circle. Kirkhart (2000) built on Shulha and Cousins's (1997) ideas "to recognize how a more inclusive view of evaluation influence has positive implication for the evaluation profession as a whole" (p. 20). We now build on these ideas collectively, to see how two key developments provide insight into the continued evolution of the concept of use in the field of evaluation. The evolution has led to transformations in evaluation thinking and practice. As Daugherty (2007) stated, "transformation is taking action to move beyond our current form. True transformation requires true willingness, converted into action" (p.xxi). Because of the transformations in the field of program evaluation, evaluators and scholars are poised to continue to use as broad a lens as they can, to innovate within the evaluation contexts. Innovation is an opportunity to act as bricoleurs, pulling from ideas and techniques to shape new understandings. Denzin and Lincoln (2005) described a bricoleur as one who blends together many pieces for use in new and unconventional ways. We propose a bricolage, which brings together key developments related to the study of use in evaluation with theory from the knowledge field. 


\section{THEORY FROM THE KNOWLEDGE FIELD}

$\mathrm{K}^{\star}$ is an overarching term used to describe the body of literature aimed at understanding knowledge-sharing activities. While many terms have been used to articulate the similar activities that encompass this field it is beneficial to explore two common terms used in Canada. In health care KT is largely the term used and in social sciences, including education, $\mathrm{KMb}$. A more in-depth investigation of the different terms from the knowledge field can be found in the fields of health (e.g., Graham et al., 2006; Greenhalgh \& Wieringa, 2011; Grimshaw, Eccles, Lavis, Hill \& Squires, 2012) and education (e.g., Bennet \& Bennet, 2007; Cooper, 2014; Cooper \& Levin, 2013; Fenwick \& Farrell, 2011). The following section will introduce KT and $\mathrm{KMb}$ and examine how this body of work can inform evaluation and evaluation use.

\section{Knowledge Translation}

The first article to be published using the KT term has been traced to 1971 (Greenhalgh \& Wieringa, 2011). While the concept of knowledge translation is not new, there has been a rapid proliferation of research and literature on KT in the past two decades. Evaluation use and KT have similar roots; however, the literature has largely been developed in parallel (Amo \& Cousins, 2009) with little crossover in either literature. In 2009 two special issues sought to bring these fields together. An issue of New Directions for Evaluation (Ottoson, 2009) reported on the role of change theories in evaluation, and in the same year the Canadian Journal of Program Evaluation examined how knowledge use theories could help support evaluation use (Amo \& Cousins, 2009). In Europe there is also evidence that $\mathrm{KT}$ is beginning to influence evaluation. A recent report (Bossuyt, Shaxson, \& Datta, 2014) examined the uptake of evaluations in European Union development cooperation, and one of four key learning points was that "uptake of evidence is improved by considering how knowledge is translated and brokered within an organization" (p. 7).

In Canada knowledge translation is defined as a "dynamic and iterative process that includes the synthesis, dissemination, exchange, and ethically sound application of knowledge to improve the health of Canadians, provide more effective health services and products, and strengthen the healthcare system" (Canadian Institutes of Health Research, 2016). This definition is broadly used, and both the World Health Organization (WHO) and United States Centre for Dissemination of Disability Research have adopted similar definitions (Bowen \& Graham, 2013). KT is used extensively in the health field and is closely linked to the evidence-based practice movement (Greenhalgh \& Wieringa, 2011). The KT literature makes frequent reference to the gap between what is known, as determined by researchers, and what is observed in practice; this is often referred to as the evidence-to-practice gap (Kitson \& Straus, 2010).

Within Canada, and in particular health care, the Knowledge to Action (KTA) cycle (Graham et al., 2006) is used to conceptualize knowledge translation. The Canadian Institutes of Health Research (CIHR) has adopted the KTA cycle as 
described by Graham et al. (2006) to support knowledge translation research, a fundamental part of the organization's mandate. The KTA cycle is divided into two components: knowledge creation and action. Knowledge creation includes three phases. The first represents knowledge obtained through primary research studies. The second involves knowledge synthesis or the systematic collection of existing knowledge. The final and third phase consists of tools or products that present knowledge in a way that meets the needs of identified stakeholders. It is important to note that synthesized knowledge is the core unit of the knowledge creation phase (Straus, Tetroe, \& Graham, 2009). Ultimately it is this synthesized knowledge that becomes packaged and presented to the knowledge users, indicating the start of the action phase. The action phase represents activities used to assist in the application of knowledge, with eight specific processes including the evaluation of outcomes. It is here that the literature on both evaluation and KT currently conceptualize the role for evaluation: the evaluation of KT interventions. The KTA cycle is not without its criticisms. From an evaluation perspective this narrow conceptualization essentially views evaluation in terms of outcomes rather than considering the role process evaluation may play in an earlier phase of the KTA cycle, that is, adapting knowledge to the environment and assessing barriers to knowledge use. Second, evaluation and not only research can be seen as a mechanism to transfer knowledge to individuals and organizations.

Two broad forms of KT exist: end-of-grant KT and integrated KT (Gagnon, 2009). End-of-grant KT refers to the dissemination of research findings upon project completion; most of the literature has focused on this form of KT (CIHR, 2011). From an evaluation perspective this is similar to the use of evaluation results. There is a significant body of research examining the effectiveness of specific KT strategies on health outcomes (Grimshaw et al., 2012); however, the evidence continues to remain inconclusive. In contrast, in evaluation literature there is relatively little primary research dedicated to examining what strategies support the use of evaluation results, although much theoretical literature has explored concepts related to use (Cousins \& Leithwood, 1986; Johnson et al., 2009). Integrated knowledge translation, the second broad form of KT, refers to the "active collaboration between researchers and research users in all parts of the research process" (Graham et al., 2006, p. 21). The assumption is that research findings will be more relevant and therefore implemented by the end users if they are actively involved in all phases of the research process (Bowen \& Graham, 2013; Gagnon, 2009).

\section{Knowledge Mobilization}

The concept of mobilizing knowledge relates to the activities and outputs of a process or project that builds awareness and enables the use of findings. The Social Sciences and Humanities Council (SSHRC, 2009) suggests that knowledge mobilization allows researchers to connect within and beyond academia to maximize the cultural, intellectual, social, and economic impacts of their work. The more recent SSHRC plan emphasizes maximizing the impact of research for the purposes of capturing and communicating as widely as possible. Opportunities for $\mathrm{KMb}$ 
activities exist within all of the phases or stages of a research or evaluation project and can be leveraged with thoughtful planning for purposeful actions focused on engagement. Engagement activities facilitated in participatory and collaborative approaches to program evaluation are simultaneously aspects of KMb. The focus of both $\mathrm{KMb}$ and participatory or collaborative approaches to evaluation is the bringing together of stakeholders, who work responsively to design and, to some extent, carry out projects within a given context. Both share a goal of creating and distributing knowledge in ways that are accessible and purposeful. SSHRC's Community-University Research Alliances Program that ran for over a decade highlights the principles of $\mathrm{KMb}$ through collaboration with communities and researchers (Kishchuk, 2003).

There are many other descriptions of $\mathrm{KMb}$; one of the difficulties already mentioned is connected to the medley of terminology associated with knowledge mobilization activities. There are subtle differences, but they are all terms and activities that focus on the connections between research and practice/policy. Beyond this difficulty, considerable challenges exist in explaining and promoting the utilization of findings into practice, and even when these are translated, there exist difficulties in getting findings taken up in practice settings (Graham et al., 2006). Two central KMb activities include using diverse strategies for promoting the knowledge, resources, and expertise, while also reinforcing decision making and problem solving in applied practice. $\mathrm{KMb}$ functions within and across communities, effectively joining academic scholarship with communities of practice; therefore, it is imperative that those who are mobilizing knowledge are attuned to the contexts of the areas they operate in.

$\mathrm{KMb}$ is often represented as consisting of four domains: creating (e.g., dialogue, community building), brokering (e.g., informing, linking, matching), exchanging (e.g., workshops, conferences, mentoring), and disseminating (e.g., social media, websites, blogs, presentations). Each domain is interrelated and consists of multiple activities that include informational, relational, and systems functions (Bennet \& Bennet, 2007). Within the activities of each domain, multiple media such as face-to-face, web-based, print, video, and/or performance could be used. These domains, activities, and media offer a way of thinking about KMb activities that can promote evaluation use. There are multiple ways to create, share, and use knowledge. Most important in $\mathrm{KMb}$ and in program evaluation is having a clear purpose and understanding the intended users or audiences.

\section{Informing Program Evaluation through $K^{*}$}

While $\mathrm{KT}$ and $\mathrm{KMb}$ are both about the change process, the fundamental difference is that the term KT is almost exclusively found in the health field with the ultimate goal of KT being a change in health service delivery and/or patient outcomes. While $\mathrm{KMb}$ terminology is broader, enabling its application to multiple sectors, in turn it runs the risk of not having specific outcomes. $\mathrm{K}^{\star}$ has emerged as a way of bringing together diverse strategies and approaches in the field of knowledge work. As scholars and practitioners in program evaluation, insights 
gained from $\mathrm{K}^{\star}$ offer potential for real sustainable change toward social betterment. We suggest that $\mathrm{K}^{\star}$ has three core applications that can inform evaluation use: knowledge synthesis, action, and knowledge brokering.

Knowledge Synthesis. While evaluators create knowledge using systematic inquiry processes similar to those used in research, the fundamental difference between research and evaluation lies in their purpose. Research creates knowledge that addresses identified gaps in theories or disciplinary knowledge, and evaluation creates knowledge for use in practice (Alkin \& Taut, 2003). This is an important distinction, as knowledge that is created and synthesized for action within $\mathrm{K}^{\star}$ is largely research based (Grimshaw et al., 2012; Shaxson et al., 2012). Evaluators could gain significant insights from $\mathrm{K}^{*}$ by considering how synthesized research knowledge could be integrated into evaluations: to inform program theory, to consider the evaluation results within the larger body of literature, or to potentially support and inform program development and ongoing refinements. Urban and Trochim (2009) have described a method they call systems evaluation partnership (SEP) to support the integration of research evidence into evaluations. A visual diagram of the program is created, and evaluators make connections between the program logic and research evidence. Evidence is mapped onto the program logic to support the programs theory and link the local program to the broader evidence. The SEP approach has not gained traction in the evaluation literature, but has a clear link to $\mathrm{K}^{\star}$ and is a model to consider how knowledge synthesis can be integrated into evaluation.

To effectively and efficiently integrate research evidence into evaluation, evaluators would need to have content knowledge about the program or allot time and resources to identify and synthesize relevant research evidence. With increasing emphasis on $\mathrm{K}^{\star}$ in health and education contexts it might be timely to open this discussion. There remains a widespread belief that the key to effective evaluator practice is the application of strong methodological skills, and that these skills can be equally and aptly applied to a range of contexts, programs, and fields of practice. This view is evident in the discussion regarding evaluator competencies (King, Stevahn, Ghere, \& Minnema, 2001; Stevahn, King, Ghere, \& Minnema, 2005). The Canadian Evaluation Society has expanded on this notion in requiring the demonstration of five broad evaluator competencies to receive a designation of evaluator. These competencies are reflective practice, technical practice, situational practice, management, and interpersonal practice competencies (Canadian Evaluation Society, 2013). It is particularly relevant to note that there is little if any discussion about the need for evaluators to have current content knowledge related to the evaluand or its context (Canadian Evaluation Society, 2013). The idea of content expertise raises a broader question about the role of evaluators, and we acknowledge that a KT-informed evaluation may push the boundaries of theorists and evaluators who believe that evaluators must maintain a detached orientation, and that evaluation is inherently about making judgements about a program's merit, worth, and significance (Alkin, 2004). If content expertise is not feasible, it would at least be expected that the evaluator recognize the importance of using synthesized literature 
to inform the program and evaluation. Just as methodological experts might be added to the evaluation team, content experts could be identified and included on the evaluation team.

Action. The knowledge field can also inform the strategies or processes evaluators implement to enhance use. There are now dozens of reviews from the discrete areas within the knowledge field that have examined the impact of specific $\mathrm{K}^{\star}$ strategies on healthcare practice and outcomes (e.g., Greenhalgh \& Wieringa, 2011; Ivers et al., 2012; Sudsawad, 2007) and educational outcomes (e.g., Fenwick \& Farrell, 2011; Levin, 2013). These reviews are based on high quality research and examine dozens of $\mathrm{KT}$ and $\mathrm{KMb}$ strategies. When compared to the field of $\mathrm{K}^{\star}$, there has been relatively little empirical research examining specific evaluation interventions or approaches to enhance evaluation use. Only a handful of review articles on use have been completed. Cousins and Leithwood (1986) provided the first comprehensive empirical review of use spanning the years 1971 to 1985 , and Johnson and colleagues (2009) updated this review to include the literature on evaluation use from 1986 to 2005 . Between both of these reviews, only 106 articles were found spanning more than 30 years, and much of this work was retrospective or descriptive in nature. Consider a recent systematic review on audit and feedback (Ivers et al., 2012) as a strategy to improve healthcare practice. The article included 140 studies, and all were randomized controlled trials.

For evaluators, research from the knowledge field could help identify specific strategies to adopt during and after an evaluation to support both process use and use of evaluation findings. This idea is reinforced if we consider the systematic review on audit and feedback where the authors identified feedback on professional performance contributing to small but important improvements in practice (Ivers et al., 2102). The review also outlines ways to optimize feedback to improve performance. Research such as this can provide insights for evaluation scholars and practitioners by offering specific strategies to optimize ways in which feedback can be provided to programs. The knowledge field also provides insights and examples of methodologies that could be used to further our understanding of evaluation use.

Brokering. We have identified how $\mathrm{K}^{\star}$ can support the integration of research knowledge into an evaluation and identify strategies to enhance use. However, thinking more broadly than one or two discrete practices, evaluators can draw heavily to design a $\mathrm{K}^{\star}$-informed evaluation. Donnelly and colleagues (2014) have provided an example of how such an evaluation can be designed and implemented. Drawing on both the knowledge and evaluation literature, this evaluation was designed to be intentional in facilitating the application of emerging evaluation knowledge into practice and also attended to the empirical evidence (original studies or synthesized knowledge) that grounded the program and the clinicians within the program. The evaluator in this type of evaluation is cognizant of how empirical and formalized knowledge informed each phase of the evaluation, from the development of the evaluation questions to understanding emerging and final findings in light of current research. Framing this work as a $\mathrm{K}^{\star}$ approach to 
evaluation involves the intentional and active development of opportunities for a range of stakeholders to develop the skills to engage in knowledge work. A $\mathrm{K}^{\star}$ informed evaluation also looks to facilitate connections and collaborations among knowledge networks, local researchers/evaluators, and within communities of practice. One of the key elements of Patton's utilization-focused evaluation is the identification of and engagement with intended users of the evaluation. In this approach the evaluator is connecting and developing relationships with stakeholders to enhance use (Patton, 2008). From a knowledge-brokering perspective, an evaluator could identify a broader network of intended users that would include researchers or knowledge networks.

Urban and Trochim (2009) identify evaluators as ideally situated to bridge the research-practice divide, and in a KT-informed evaluation the role of the evaluator becomes one of knowledge broker. Along with content knowledge, evaluators can respond to the knowledge needs of the program and organize, identify, summarize, and communicate relevant external evidence. This evidence may not necessarily be limited to published empirical research. Relevant evidence might include forms of stakeholders' explicit and implicit knowledge that, when examined, might inform the program, the evaluation process, and results. As a knowledge broker, the evaluator would also be aware of the potential connections between the programs to relevant knowledge and research networks/communities of practice. These connections can lead to two-way relationships where programs gain external knowledge, but also have the opportunity to translate program knowledge outward.

There are multiple potential benefits in using concepts drawn from $\mathrm{K}^{\star}$, such as assuming a knowledge broker's role. As organizations gain interest and awareness of $\mathrm{K}^{*}$, evaluators can play a critical role facilitating linkages between research and practice. Evaluators can also support their practice by drawing on the growing research in $\mathrm{K}^{*}$.

\section{DISCUSSION}

"In theory, there is no difference between theory and practice but in practice there is." Yogi Berra

Evaluation is uniquely positioned as integrating theory and practice in the pursuit of systematic forms of inquiry and decision making. Having introduced concepts from the field of $\mathrm{K}^{\star}$, it is important to return to the two key developments that we have identified in the field of evaluation and reexamine these from the $\mathrm{K}^{\star}$ lens.

\section{Key Theme One: Individual and Organizational Learning}

Of particular relevance to the domain of individual and organizational learning is the concept of IKT-integrated knowledge translation. As evidence for researcher-initiated end-of-grant $\mathrm{K}^{\star}$ activities remains inconclusive (e.g., Grimshaw et al., 2012; Grimshaw et al., 2004; Menon, Korner-Bitensky, Kastner, McKibbon, \& Straus, 2009; Mitton, Adair, McKenzie, Patten, \& Waye-Perry, 2007), there is 
increasing recognition of the need to develop collaborative partnerships between researchers and end-users to better understand local context and knowledge needs to facilitate knowledge use (Bowen \& Graham, 2013; Kitson \& Bisby, 2008; Kothari, Birch, \& Charles, 2005). In evaluation, process use could be considered similar to IKT. To date there has been relatively little empirical research conducted that has explored the relationship between process use and the use of evaluation results (Amo \& Cousins, 2007). While there have been many articles about process use since being formally described by Patton (1998), much of the literature is theoretical in nature, with few empirical studies examining the relationship between process use and the use of evaluation results. Amo and Cousins (2007) conducted the only known literature review on process use. They identified 18 studies from 1984 to 2005 and found that process use resulted in enhanced learning about evaluation, changes in behaviours regarding evaluation, and changes in attitudes about evaluation (Amo \& Cousins, 2007). More recent literature has sought to further understanding types of process use (Baptiste, 2010) and explore process use within the larger concept of evaluation capacity building (Cousins, Goh, Elliott, \& Bourgeois, 2014). However, from a $\mathrm{K}^{\star}$ perspective it is also critical to examine knowledge generation about the program, changes to program delivery, and changes in attitudes and culture toward new knowledge.

Research utilization is situated socially, and "interactive approaches currently seem to show most promise in improving the use of research" (Davies, Nutley, \& Walter, 2008, p. 152). If an evaluator adopts a knowledge broker role, stakeholder engagement can be broadened beyond immediate program stakeholders to include broader knowledge networks and communities of practice (Donnelly et al., 2014).

$\mathrm{K}^{\star}$ can inform ECB in several ways. Cousins and colleagues (2013) have identified that the most underdeveloped area of ECB theory, practice, and research is evaluation use. This is clearly evidenced if we look at a list of 36 potential ECB objectives categorized by the knowledge, skills (behaviours), and affective domains that have been developed by Preskill and Boyle (2008). Thirtythree of these objectives focus on building the individual's or organization's capacity to conduct evaluation, for example, enhancing skills in data collection, interpreting results, and developing a logic model. Only three relate to developing the capacity to use the evaluation findings, for example, "communicate and report evaluation processes and findings using a variety of strategies" (Preskill and Boyle, 2008, p. 450). From an ECB and $\mathrm{K}^{\star}$ perspective, building the capacity to use the evaluations is critical.

ECB also requires the conscious use of evidence-based strategies to support use, and the $\mathrm{K}^{\star}$ literature, as identified earlier, can offer a rich source of evidence to draw upon. The intentionality requires a focus on the context of the user, the range of stakeholders who might use the information as well as an understanding of their needs and interests, and the range of potential uses and misuses. Knowing that participatory approaches are fundamental to support use, it is important to simultaneously attend to continually supporting the use of emerging and 
contextual information and the end of project findings. Developing intentional processes to support the translation of emerging knowledge to the program and use of findings beyond the project completion align with $\mathrm{K}^{\star}$. There are multiple $\mathrm{K}^{\star}$ frameworks and models that can be used to support the intentional use of strategies and processes to support evaluation use. The KTA cycle (Graham et al., 2006) described earlier is just one of many. ECB is much more complex than simply looking at stakeholder engagement or process use and is an excellent lens through which to consider the complexities of $\mathrm{K}^{\star}$ in evaluation. Exploring use in ECB will be an important line of inquiry in the field of evaluation.

\section{Key Theme Two: Evaluation Influence}

When we look at the concept of influence, the evaluation itself is seen as a change process with the ultimate goal of social betterment (Kirkhart, 2000; Mark \& Henry, 2004). For evaluation to support its claim to be a change process, the field must begin to identify the specific outcomes that the evaluation will influence. If we look at the definition of KT, for example, the ultimate goal of any KT strategy is to change health delivery or health outcomes (CIHR, 2016), akin to social betterment within a healthcare context. KT research, therefore, provides evidence to the healthcare field on what translation strategies change health outcomes.

Mark and Henry (2004) offer evaluators a model to identify specific pathways; an evaluation can influence a program at three levels: individual, interpersonal, and collective (organizational). Pathways link evaluation activities and influence. $\mathrm{K}^{\star}$ is about change processes, and the pathways of influence is an excellent general model that evaluators can use to explicitly articulate how they anticipate an individual evaluation will influence one or more levels and then plan evaluation activities to support this assertion. For evaluation researchers, social betterment needs to be operationalized in each program context, and this framework can help develop research designs to examine the impact of specific evaluation activities on articulated outcomes. While much of the current research on use is descriptive in nature or retrospective, this body of work holds much promise to help guide the field of evaluation in studying the role of evaluation itself, a strategy to translate knowledge. Using $\mathrm{K}^{\star}$ terminology would help to connect the current silos of work on evaluation use and across the knowledge field.

\section{CONCLUSION}

In 1989, Greene, Caracelli, and Graham concluded that "the inevitable organizational, political, and interpersonal challenges of program evaluation mandate the use of multiple tools" (p. 255). A similar argument could be made here; an understanding of $\mathrm{K}^{*}$ is a theoretical positioning that brings with it multiple tools, processes, and different ways of thinking about knowledge that can, collectively, lead to new understanding. The integration of $\mathrm{K}^{*}$ is another way of understanding programmatic change and enhancing the use and influence of evaluation. As 
evaluation considers $\mathrm{K}^{*}$ and the impact on both evaluation practice and research, two questions can be asked and investigated in the future.

Question 1: What can evaluation learn from $K^{*}$ ? First, the evaluation community has a longstanding interest in use. A focus on $\mathrm{K}^{\star}$ is a natural extension of this interest and can serve as a catalyst to build further skills and knowledge to foster use. Second, this question encourages evaluation to consider terms for use beyond the evaluation literature. Use of $\mathrm{K}^{\star}$ terminology can bridge the gap between the currently siloed bodies of knowledge on use and KT. Third, uniting these fields enables evaluation to more broadly contribute to the rapidly growing field of $\mathrm{K}^{\star}$. Fourth, inquiring into $\mathrm{K}^{\star}$ serves to legitimize evaluation as a systematic form of inquiry in health care. Finally, investigating $\mathrm{K}^{\star}$ and evaluation can facilitate research on the area of use. There is a dearth of quantitative studies demonstrating how evaluation changes health outcomes or practice behaviours. Evaluation would benefit from drawing on the stronger methodological studies found in health care and their high demands for strong empirical evidence.

Question 2: What can $K^{\star}$ learn from evaluation? Just as evaluation can benefit from $\mathrm{K}^{\star}$ literature, so too can evaluation positively affect $\mathrm{K}^{\star}$. Evaluation offers another approach to participatory forms of inquiry that may be more accessible to healthcare programs and organizations. Research is traditionally carried out in separate institutions, while evaluation is conducted in the organizational contexts where the programs are operationalized. Evaluation has the knowledge, skill set, and practice standards (Yarbrough et al., 2011) to support program-based inquiry. A major contribution evaluation can provide to health care and $\mathrm{K}^{\star}$ are the welldeveloped theoretical and conceptual frameworks on use. Specifically, the work on process use can offer a jumping-off point for further research on IKT and other forms of participatory research.

\section{REFERENCES}

Alkin, M. C. (2004). Evaluation roots: Tracing theorists' views and influences. Thousand Oaks, CA: Sage.

Alkin, M. C., \& Taut, S. (2003). Unbundling evaluation use. Studies in Educational Evaluation, 29(1), 1-12. http://dx.doi.org/10.1016/S0191-491X(03)90001-0

Amo, C., \& Cousins, J. B. (2007). Going through the process: An examination of the operationalization of process use in empirical research on evaluation. New Directions for Evaluation, 2007(116), 5-26. http://dx.doi.org/10.1002/ev.240

Amo, C., \& Cousins, J. B. (2009). Reconnecting knowledge utilization and evaluation utilization domains of inquiry. Canadian Journal of Program Evaluation, 23(1), 81-85.

Arnold, M. E. (2006). Developing evaluation capacity in extension 4-H field faculty: A framework for success. American Journal of Evaluation, 27(2), 257-269. http://dx.doi. org/10.1177/1098214006287989

Atkinson, D. D., Wilson, M., \& Avula, D. (2005). A participatory approach to building capacity of treatment programs to engage in evaluation. Evaluation and Program Planning, 28(3), 329-334. http://dx.doi.org/10.1016/j.evalprogplan.2005.04.012 
Baptiste, L. J. (2010). Process use across evaluation approaches: An application of Q methodology in program evaluation (Doctoral dissertation). Kent State University, Ohio.

Bennet, A., \& Bennet, D. (2007). Knowledge mobilization in the social sciences and humanities: Moving from research to action. Frost, WV: MQI Press.

Bossuyt, J., Shaxson, L., \& Datta, A. (2014). Assessing the uptake of strategic evaluations in EU Development Cooperation. European Union. Retrieved from https:/ec.europa. eu/europeaid/sites/devco/files/strategic-evaluation-uptake-study-1331-mainreport-201406_en.pdf

Bowen, S. J., \& Graham, I. D. (2013). From knowledge translation to engaged scholarship: Promoting research relevance and utilization. Archives of Physical Medicine and Rehabilitation, 94(1), S3-S8. http://dx.doi.org/10.1016/j.apmr.2012.04.037

Brandon, P. R., \& Fukunaga, L. L. (2013). The state of the empirical research literature on stakeholder involvement in program evaluation. American Journal of Evaluation, 35(1), 1098214013503699.

Canadian Evaluation Society. (2013). Competencies for Canadian evaluation practice. https://evaluationcanada.ca/txt/2_competencies_cdn_evaluation_practice.pdf

Canadian Institutes of Health Research. (2011). Funding overview. http://www.cihr-irsc. gc.ca/e/37788.html

Canadian Institutes of Health Research. (2016). More about knowledge translation at CIHR: Knowledge translation definition. Retrieved from http://www.cihr-irsc.gc.ca/e/45321. html

Christie, C. A. (2007). Reported influence of evaluation data on decision makers' actions: An empirical examination. American Journal of Evaluation, 28(1), 8-25. http://dx.doi. org/10.1177/1098214006298065

Compton, D., Baizerman, M., Preskill, H., Rieker, P., \& Miner, K. (2001). Developing evaluation capacity while improving evaluation training in public health: The American Cancer Society's Collaborative Evaluation Fellows Project. Evaluation and Program Planning, 24(1), 33-40. http://dx.doi.org/10.1016/S0149-7189(00)00045-8

Compton, D. W., \& Baizerman, M. (2007). Defining evaluation capacity building. American Journal of Evaluation, 28(1), 118-119. http://dx.doi.org/10.1177/1098214006298172

Contandriopoulos, D., \& Brousselle, A. (2012). Evaluation models and evaluation use. Evaluation, 18(1), 61-77. http://dx.doi.org/10.1177/1356389011430371

Cooper, A. (2014). Knowledge mobilisation in education across Canada: A cross-case analysis of 44 research brokering organisations. Evidence \& Policy: A Journal of Research Debate and Practice, 10(1), 29-59. http://dx.doi.org/10.1332/174426413X662806

Cooper, A., \& Levin, B. (2013). Research use by leaders in Canadian school districts. International Journal of Education Policy and Leadership, 8(7), 1-15.

Cousins, J. B., \& Earl, L. M. (1992). The case for participatory evaluation. Educational Evaluation and Policy Analysis, 14(4), 397-418. http://dx.doi.org/10.3102/0162373701 4004397

Cousins, J. B., Goh, S. C., Clark, S., \& Lee, L. E. (2004). Integrating evaluative inquiry into the organizational culture: A review and synthesis of the knowledge base. Canadian Journal of Program Evaluation, 19, 99-141. 
Cousins, J. B., Goh, S. C., Elliott, C. J., \& Bourgeois, I. (2014). Framing the capacity to do and use evaluation. New Directions for Evaluation, 2014(141), 7-23. http://dx.doi. org/10.1002/ev.20076

Cousins, J. B., \& Leithwood, K. A. (1986). Current empirical research on evaluation utilization. Review of Educational Research, 56(3), 331-364. http://dx.doi. org/10.3102/00346543056003331

Cousins, J. B., \& Shulha, L. M. (2006). A comparative analysis of evaluation utilization and its cognate field of inquiry: Current issues and trends. In I. F. Shaw, J. C. Greene, \& M. M. Mark (Eds.), The Sage handbook of evaluation (pp. 266-291). London, UK: Sage. http://dx.doi.org/10.4135/9781848608078.n12

Cousins, J. B., Whitmore, E., \& Shulha, L. (2013). Arguments for a common set of principles for collaborative inquiry in evaluation. American Journal of Evaluation, 34(1), 7-22. http://dx.doi.org/10.1177/1098214012464037

Daugherty, A. (2007). The power within: From neuroscience to transformation. Dubuque, IA: Kendall/Hunt.

Davies, H., Nutley, S., \& Walter, I. (2008). Why "knowledge transfer" is misconceived for applied social research. Journal of Health Services Research \& Policy, 13(3), 188-190. http://dx.doi.org/10.1258/jhsrp.2008.008055

Davison, C. M. (2009). Knowledge translation: Implications for evaluation. In J. M. Ottoson and P. Hawe (Eds.), Understanding utilization, diffusion, implementation transfer, and translation: New Directions for Evaluation, 80, 87-105. http://dx.doi.org/10.1002/ev.315

Denzin, N. K., \& Lincoln, Y. S. (2005). The Sage handbook of qualitative research. London, UK: Sage.

Donnelly, C., Letts, L., Klinger, D., \& Shulha, L. (2014). Supporting knowledge translation through evaluation: Evaluator as knowledge broker. Canadian Journal of Program Evaluation, 29(1), 36-61. http://dx.doi.org/10.3138/cjpe.29.1.36

Duffy, J. L., \& Wandersman, A. (2007). A review of research on evaluation capacity-building strategies. Paper presented at the annual conference of the American Evaluation Association, Baltimore, MD.

Fenwick, T., \& Farrell, L. (Eds.). (2011). Knowledge mobilization and educational research: Politics, languages and responsibilities. Abingdon, UK: Routledge.

Fetterman, D., Rodríguez-Campos, L., Wandersman, A., \& O’Sullivan, R. G. (2014). Collaborative, participatory, and empowerment evaluation: Building a strong conceptual foundation for stakeholder involvement. Approaches to evaluation (A response to Cousins, Whitmore, and Shulha (2013). American Journal of Evaluation, 35(1), 144-148. http://dx.doi.org/10.1177/1098214013509875

Fleischer, D., \& Christie, C. (2009). Evaluation use. American Journal of Evaluation, 30(2), 158-175. http://dx.doi.org/10.1177/1098214008331009

Gagnon, M. L. (2009). Knowledge dissemination and exchange of knowledge. In S. Straus, J. Tetroe, \& I. Graham (Eds.), KT in health care: Moving from evidence to practice (pp. 235-248). West Sussex, UK: John Wiley.

Graham, I. D., Logan, J., Harrison, M. B., Straus, S. E., Tetroe, J., Caswell, W., \& Robinson, N. (2006). Lost in knowledge translation: Time for a map? Journal of Continuing 
Education in the Health Professions, 26(1), 13-24. Retrieved from http://onlinelibrary. wiley.com/doi/10.1002/chp.47/pdf. http://dx.doi.org/10.1002/chp.47

Greene, J., Caracelli, V., \& Graham, W. (1989). Toward a conceptual framework for mixedmethod evaluation designs. Educational Evaluation and Policy Analysis, 11(3), 255274. http://dx.doi.org/10.3102/01623737011003255

Greene, J. G. (1988). Stakeholder participation and utilization in program evaluation. Evaluation Review, 12(2), 91-116. http://dx.doi.org/10.1177/0193841X8801200201

Greenhalgh, T., \& Wieringa, S. (2011). Is it time to drop the knowledge translation metaphor?: A critical literature review. Journal of the Royal Society of Medicine, 104(12), 501-509. http://dx.doi.org/10.1258/jrsm.2011.110285

Grimshaw, J. M., Eccles, M. P., Lavis, J. N., Hill, S., \& Squires, J. E. (2012). Knowledge translation of research findings. Implementation Science: IS, 7(1), 1-17. Retrieved from http://www.implementationscience.com/content/7/1/50 http://dx.doi. org/10.1186/1748-5908-7-50

Grimshaw, J. M., Thomas, R. E., MacLennan, G., Fraser, C. R., Ramsay, L., Vale, L., . . Donaldson, C. (2004). Effectiveness and efficiency of guideline dissemination and implementation strategies. Health Technology Assessment, 8(6), 1-7. http://dx.doi. org/10.3310/hta8060

Harnar, M. A., \& Preskill, H. (2007). Evaluators' description of process use: An exploratory study. In J. B. Cousins (Ed.), Process use: Theory, research and practice. No. 116 (pp. 27-44). San Francisco, CA: Jossey-Bass. http://dx.doi.org/10.1002/ev.241

Herbert, J. L. (2014). Researching evaluation influence: A review of the literature. Evaluation Review, 38(5), 388-419. http://dx.doi.org/10.1177/0193841X14547230

Henry, G. T., \& Mark, M. M. (2003). Beyond use: Understanding evaluations' influence on attitudes and actions. American Journal of Evaluation, 24(3), 293-314. http://dx.doi. org/10.1177/109821400302400302

House, E. R., \& Howe, K. R. (1999). Values in evaluation and social research. Thousand Oaks, CA: Sage.

Ivers, N., Jamtvedt, G., Flottorp, S., Young, J. M., Odgaard-Jensen, J., French, S. D. . . Oxman, A. D. (2012). Audit and feedback: Effects on professional practice and healthcare outcomes. Cochrane Database of Systematic Reviews, 6(6). http://dx.doi. org/10.1002/14651858.CD000259.pub3

Johnson, K., Greenseid, L. O., Toal, S. A., King, J. A., Lawrenz, F., \& Volkov, B. (2009). Research on evaluation use: A review of the empirical literature from 1986 to 2005. American Journal of Evaluation, 30(3), 377-410. http://dx.doi. org/10.1177/1098214009341660

Jonson, J. L., Guetterman, T., \& Thompson Jr, R. J. (2014). An integrated model of influence: Use of assessment data in higher education. Research \& Practice in Assessment, 9, 1-13.

King, J. A., \& Pechman, E. M. (1984). Pinning a wave to the shore: Conceptualizing evaluation use in school systems. Educational Evaluation and Policy Analysis, 6(3), 241-251. http://dx.doi.org/10.3102/01623737006003241

King, J. A., Stevahn, L., Ghere, G., \& Minnema, J. (2001). Toward a taxonomy of essential evaluator competencies. American Journal of Evaluation, 22(2), 229-247. 
Kirkhart, K. E. (2000). Reconceptualizing evaluation use: An integrated theory of influence. New Directions for Evaluation, 2000(88), 5-23.

Kishchuk, N. (2003). Performance report: Phase 1 of the Community-University Research Alliances (CURA) program. Retrieved from http://www.sshrc-crsh.gc.ca/about-au_ sujet/publications/cura_e.pdf

Kitson, A., \& Bisby, M. (2008). Speeding up the spread: Putting KT research into practice and developing an integrated KT collaborative research agenda. Alberta Heritage Foundation for Medical Research. http://cihc.ca/files/members/pke/SpeedingUpTheSpread_ KT08.pdf

Kitson, A., \& Straus, S. E. (2010). The knowledge-to-action cycle: Identifying the gaps. Canadian Medical Association Journal, 182(2), E73-E77. http://dx.doi.org/10.1503/ cmaj.081231

Kothari, A., Birch, S., \& Charles, C. (2005). "Interaction" and research utilization in health policies and programs: Does it work? Health Policy (Amsterdam), 71(1), 117-125. http://dx.doi.org/10.1016/j.healthpol.2004.03.010

Labin, S. N., Duffy, J., Meyers, D. C., Wandersman, A., \& Lesesne, C. A. (2012). A research synthesis of the evaluation capacity building literature. American Journal of Evaluation, 33(3), 307-338. http://dx.doi.org/10.1177/1098214011434608

Lawrenz, F., Thomas, K., \& Clarkson, L. C. (2008). Evaluation capacity building in the schools: Administrator-led and teacher-led perspectives. Canadian Journal of Program Evaluation, 23, 61-82.

Levin, B. (2013). To know is not enough: Research knowledge and its use. Review of Education, 1(1), 2-31. http://dx.doi.org/10.1002/rev3.3001

Mark, M. M., \& Henry, G. T. (2004). The mechanisms and outcomes of evaluation influence. Evaluation, 10(1), 35-57. http://dx.doi.org/10.1177/1356389004042326

Menon, A., Korner-Bitensky, N., Kastner, M., McKibbon, K. A., \& Straus, S. (2009). Strategies for rehabilitation professionals to move evidence based knowledge into practice: A systematic review. Journal of Rehabilitation Medicine, 41(13), 1024-1032. http:// dx.doi.org/10.2340/16501977-0451

Mitton, C., Adair, C. E., McKenzie, E., Patten, S. B., \& Waye Perry, B. (2007). Knowledge transfer and exchange: Review and synthesis of the literature. Milbank Quarterly, 85(4), 729-768. http://dx.doi.org/10.1111/j.1468-0009.2007.00506.x

Ottoson, J. M. (2009). Knowledge-for-action theories in evaluation: Knowledge utilization, diffusion, implementation, transfer, and translation. New Directions for Evaluation, 2009(124), 7-20. http://dx.doi.org/10.1002/ev.310

Patton, M. Q. (1998). Discovering process use. Evaluation, 4(2), 225-233. http://dx.doi. org/10.1177/13563899822208437

Patton, M. Q. (2007). Process use as a usefulism. New Directions for Evaluation, 2007(116), 99-112. http://dx.doi.org/10.1002/ev.246

Patton, M. Q. (2008). Utilization-focused evaluation (4th ed.). Los Angeles, CA: Sage.

Patton, M. Q., \& Hopson, R. K. (Ed.) (2000). Overview: Language matters. How and why language matters in evaluation, New Directions for Evaluation, 2000(86), 5-16. http:// dx.doi.org/10.1002/ev.1168 
Preskill, H., \& Boyle, S. (2008). A multidisciplinary model of evaluation capacity building. American Journal of Evaluation, 29(4), 443-459. http://dx.doi. org/10.1177/1098214008324182

Preskill, H., Zuckerman, B., \& Matthews, B. (2003). An exploratory study of process use: Findings and implications for future research. American Journal of Evaluation, 24(4), 423-442. http://dx.doi.org/10.1177/109821400302400402

Rich, R. F. (1997). Measuring knowledge utilization: Processes and outcomes. Knowledge, Technology \& Policy, 10(3), 11-24. http://dx.doi.org/10.1007/BF02912504

Shaxson, L., Bielak, A., Ahmed, I., Brien, D., Conant, B., Fisher, C., . . . \& Weaving, R. (2012). Expanding our understanding of $\mathrm{K}^{\star}(\mathrm{Kt}, \mathrm{KE}, \mathrm{Ktt}, \mathrm{KMb}, \mathrm{KB}, \mathrm{KM}$, etc.): A concept paper emerging from the $\mathrm{K}^{\star}$ conference held in Hamilton, Ontario, Canada, April 2012. Retrieved from http://inweh.unu.edu/wp-content/uploads/2012/01/ KStar_ConceptPaper_FINALWEB.pdf

Shulha, L. M., \& Cousins, J. B. (1997). Evaluation use: Theory, research and practice since 1986. American Journal of Evaluation, 18(1), 195-208. http://dx.doi. org/10.1177/109821409701800121

Shulha, L. M., Whitmore, E., Cousins, J. B., Gilbert, N., \& al Hudib, H. (2016). Introducing evidence-based principles to guide collaborative approaches to evaluation: Results of an empirical process. American Journal of Evaluation, 37(2), 193-215. http://dx.doi. org/10.1177/1098214015615230

Social Science Humanities Research Council. (2009). SSHRC's Knowledge Mobilization Strategy, 2009-2011. https://www.ucalgary.ca/research/files/research/sshrc_knowledge_ mobilization.pdf

Stevahn, L., King, J. A., Ghere, G., \& Minnema, J. (2005). Establishing essential competencies for program evaluators. American Journal of Evaluation, 26(1), 43-59.

Stockdill, S. H., Baizerman, M., \& Compton, D.W. (2002). Toward a definition of ECB process: A conversation with the ECB literature. New Directions for Evaluation, 2002(93), 7-26. http://dx.doi.org/10.1002/ev.39

Straus, S., Tetroe, J., \& Graham, I. (Eds.). (2009). Knowledge translation in health care: Moving from evidence to practice. West Sussex, UK: John Wiley \& Sons. http://dx.doi. org/10.1002/9781444311747

Suchman, E. A. (1967). Principles and practice of evaluative research: An introduction to social research. New York, NY: Appleton-Century-Crofts.

Sudsawad, P. (2007). Knowledge translation: Introduction to models, strategies and measures. Austin, TX: Southwest Educational Development Laboratory, National Center for Dissemination of Disability Research.

Taut, S. (2008). What have we learned about stakeholder involvement in program evaluation? Studies in Educational Evaluation, 34(4), 224-230. http://dx.doi.org/10.1016/j. stueduc.2008.10.007

Taylor-Powell, E., \& Boyd, H. H. (2008). Evaluation capacity building in complex organizations. New Directions for Evaluation, 2008(120), 55-69. http://dx.doi.org/10.1002/ev.276

Urban, J. B., \& Trochim, W. (2009). The role of evaluation in research-Practice integration working toward the “Golden Spike." American Journal of Evaluation, 30(4), 538-553. http://dx.doi.org/10.1177/1098214009348327 
Weiss, C. H. (1972). Methods for assessing program effectiveness. Englewood Cliffs, NJ: Prentice Hall.

Weiss, C. H. (1981). Measuring the use of evaluation. In J. A. Ciarlo (Ed.), Utilizing evaluation: Concepts and measurement techniques (pp. 17-33). Beverly Hills, CA: Sage.

Weiss, C. H. (1998). Evaluation methods for studying program. Upper Saddle River, NJ: Prentice Hall.

Yarbrough, D. B., Shulha, L. M., Hopson, R. K., \& Caruthers, F. A. (2011). The program evaluation standards: A guide for evaluators and evaluation users (3rd ed.). Thousand Oaks, CA: Sage.

\section{AUTHOR INFORMATION}

Catherine Donnelly is an Associate Professor at the School of Rehabilitation Therapy at Queen's University. Her clinical and research interests are focused on team-based primary care, with a focus on understanding how evaluation can support organizational learning and knowledge translation.

Michelle Searle holds a PhD from Queen's University and works as an independent educational researcher and evaluator as well as an instructor at both Western University and Queen's University. Her research is focused on educational evaluations that promote learning with multiple stakeholders to enhance evaluation use. She draws from her background as an arts educator to interweave creative practices into program evaluation contexts. 